\title{
Conceptual design of the mobile granulation line for production fertilizers from digestates and ash mixtures
}

\author{
Marek Wróbel ${ }^{1, *}$, Marcin Jewiarz, Krzysztof Mudryk, Jarosław Frączek, and Krzysztof \\ Dziedzic \\ ${ }^{1}$ University of Agriculture in Krakow, Department of Mechanical Engineering and Agrophysics, 120 \\ Balicka st. 30-149 Kraków, Poland
}

\begin{abstract}
Paper presents a concept of the mobile line for the production of granulated fertilizer from digestates and ash mixtures. The main assumption of the designed line is its mobility which allows line work in the place of production of digestate. The premise for developing such model of line was the fact that the transport of highly hydrated digestate, as well as its dried form, is not advisable for economic reasons. More advantageous solution is to collect the digestate at the place of its production and it is processed into a fertilizer. Loose components, characterized by high bulk density, can be delivered to the place of production and the same means of transport can be used to transport the produced fertilizer to warehouse. This production model allows to process the digestate produced in several biogas plants, using one production line and reducing the cost of production. of fertilizer granules and the mobile line is transported to the next post-fermentation production point. Based on an analysis of the raw material characteristics and preliminary research on the raw materials mixture granulation process it was assumed that the stage of $3 \mathrm{hrs}$ mixture stabilization time is required in the line.
\end{abstract}

\section{Introduction}

A digestate is generated in a biogas plant in anaerobic methane fermentation process. Substrates in the fermentation process is subject to the following transformations: reduction of content of organic substance, decomposition of odour generating compounds, solid particles defragmentation, improvement of dehydration ability and fractional hygienization with considerably low losses of fertilizer components [1,2].

Remains after the process digestate includes: biomass of microorganisms which carry out the fermentation process, non-fermented organic compounds and mineral components. These substances are very precious from the fertilization point of view, because they include $\mathrm{N}, \mathrm{P}, \mathrm{K}$ in the mineral form directly available for plants. Moreover, the content of organic

\footnotetext{
* Corresponding author: marek.wrobel@urk.edu.pl
} 
matter which is subject to mineralization is a source of nutrients and positively influences the physical and chemical properties of soils improving thus their productivity.

From manure and different types of biomass, content: general nitrogen - 3.4-4.0; N-NH4 - 2.4-2.9; $\mathrm{P}-0.8-1.2 ; \mathrm{K}-2.7-3.1$ - (values provided in $\mathrm{g} \cdot \mathrm{l}^{-1}$ ) [3].

From an economic point of view, transportation of non-processed digestate at the distance exceeding $10 \mathrm{~km}$ from the biogas plant is non-profitable if it is going to be used as fertilizer [4].

So another, way of using digestate for fertilization purposes is searched for. One of it is granular organic and mineral fertilizers based on digestates and mineral substance. Seems to the best component for this purpose it's fly ash from professional energy industry installations, where only biomass is combustion. This kind of ash may be used as an good fertilizer [5]. Positive fertilization effects may be also achieved using mixtures of ash with organic substances $[6,7]$.

Mentioned raw materials, due of his origin, have different and varied physical properties such as: size distribution, density, porosity which significantly influence on the quality of obtained granulates $[8,9]$.

In order to be able to produce granulated fertilizer from mixtures based on ash and digestate with the addition of other valorizing components, the designed technological line must be able comprehensive processing of raw materials into granules in the form of pellets. Due to the properties of raw materials, it must enable thorough mixing of raw materials in various proportions, stabilization of the obtained mixtures in order to equalize the moisture of raw materials and also agglomeration, stabilization, purification and packaging of the obtained granulate. Designed line is supposed to have the character of a mobile line. The work presents the concept of a line that meets the above assumptions.

\section{Characterization of the raw materials and their mixtures}

The basic materials will be ash from the combustion of biomass in industrial installations and the digestate from biogasification installations for agricultural biomass and residues from slaughter of animals. Sulfur, urea and phosphorite were selected as valorizing additives. Digestate share in the mixture will be $25-75 \%$, sulfur and urea up to $5 \%$ and phosphorite up to $15 \%$.

The results of the tests carried out on laboratory scale have shown that the optimal moisture content of the raw material mixtures is at the level $18 \%$, and the acceptable level is $20 \%$. The working humidity of ash and valorizing additives is about $5 \%$. Therefore, to prepare mixtures with the assumed share of digestate and assumed moisture levels, digestate should have dedicated batch moisture (depending on the produced mixture between 21.6 $45.7 \%$ ). So digestate moisture is much higher than the moisture of the target mixture. To make the components of the mixtures obtain the required moisture a stabilization during time of 3 hours is required (value obtained on the laboratory tests).

Raw materials have a granulometric composition, which does not cause problems during granulation, and therefore they do not require additional grinding.

\section{Project assumptions}

Knowledge of raw materials parameters and interactions between them and also knowledge of its agglomeration process allowed the following assumptions and design requirements have been made:

- Line should be built on a car trailer, on which all the elements of line, necessary for its work are transported: a mixture preparation unit, granulator with a cooler, conveyors, raw 
material acceptance points and final product packaging unit, platforms, safety barriers, etc.

- Digestate drying and milling systems are not part of the line (it can be a stationary system, located in a biogas plant or a separately mobile system).

- The power supply system (power generator) is a separate mobile unit.

- Line equipment includes a forklift that supports the line during work and during preparation for and after work. It's transported on the trailer with the line.

- Estimated line efficiency is 0.6 - $08 \mathrm{t}$ per hour of final granulate.

- The operation of the line is planned in a continuous mode, which forces the use of appropriate devices.

- Valorising components are supplied in individual packages stacked on pallets. The ash is delivered in a BIG-BAG packaging.

- The digestate with required moisture is delivered to the line acceptance point with the loader (equipment of the plant in which the production is carried out) or the conveyor directly from the dryer.

- The line should be protected against dust escaping from it and should not generate postproduction waste.

- The final product will be packaged in BIG-BAG.

- Prepared fertilizer mixture, before granulation requires at least 3 hour stabilization.

- The line should have automatic control with the ability of regulate the performance of line units.

Accordingly, the mobile line should consist of the following units:

- Transport - delivering the line to the workplace.

- Preparing the mixture - implementing processes dosing and mixing of components and mixtures stabilization.

- Agglomeration - granulation prepared and stabilized mixtures.

- Cooling and stabilizing - performing processes of screening, cooling, stabilization and packaging of produced fertilizers.

The line must be equipped with additional devices, such as:

- Transport systems for raw materials, mixture and final product.

- System for separating dust and fines from granulates and filtration of technological air.

- Platforms, ladders, railings, stands ect. for comfort, quality and safety of work.

- Protection of engines and gears against overload.

\section{Concept of the mobile granulation line}

Based on the assumptions, a flowchart of the planned line was developed (Figure 1.), which illustrates the operations of processing the raw material and flow direction. There are pointed places where raw materials are supplied to the line (ash, valorising components, and digestate). The scheme also includes a technological air filtration system, with an indication of point from which the polluted air is captured and which receives dust and fines. It was also marked which elements of line remain on the transport trailer during work and which are placed outside of it. 


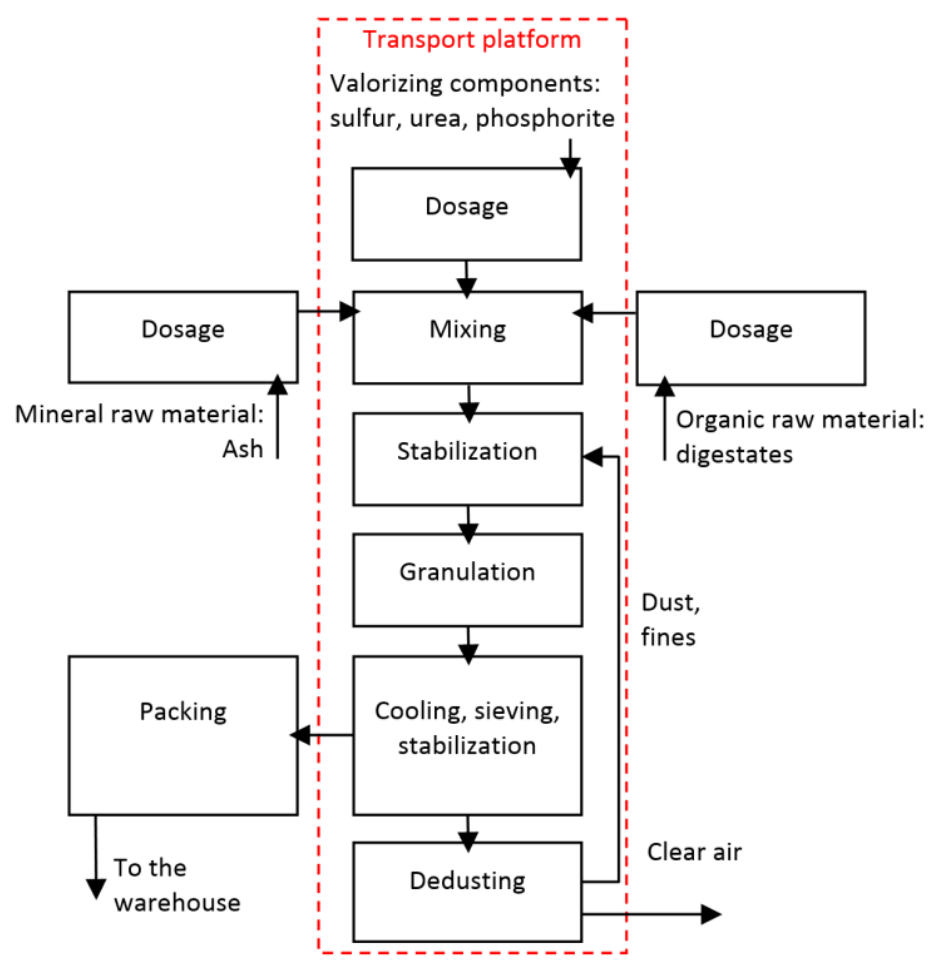

Fig. 1. Block diagram of the projected technological line.

The following technical solutions are proposed for each stage of granulated fertilizer production line (numbering in accordance with the designations in Figure 2 and Figure 3):

1. Ash in BIG-BAG unloading station.

2. Ash feeder - screw conveyor.

3. A set of tanks dispensing valorising components along with a conveyor supplying loose components to the mixer (No. 14).

4. Mixtures stabilization tank equipped with a screw conveyor feeding the mixture to the conditioner of the granulator (No. 7) and a screw system for uniform filling of the tank

5. Digestates feed station (hopper with horizontal screw conveyor)

6. Granulates coolers dedusting system (fan, cyclone, screw conveyor)

7. Ring granulator with conditioner.

8. A set of conveyors supplying raw granules into coolers (No. 9), conveyor with corrugated belt and horizontal belt conveyor with a material distributor for two coolers.

9. Pellet cooling system ( 2 drum-sieve cooler equipped with a horizontal screw conveyor collecting fines and feeding it to the dust extraction system (No. 6).

10. A set of conveyors with corrugated tape feeding granules to the BIG-BAG filling station (No. 11).

11. BIG-BAG filling station (two racks with BIG-BAG carrier, granulate distributor).

12. Transport trailer - folding forklift can be transported in a pallet box or hung at the rear of the trailer.

13. Digestates feeder - screw conveyor.

14. Unit for the fertilizer mixture preparation (twin-shaft mixer).

15. Mixture feeder to stabilizing tank (No. 4) - screw conveyor. 


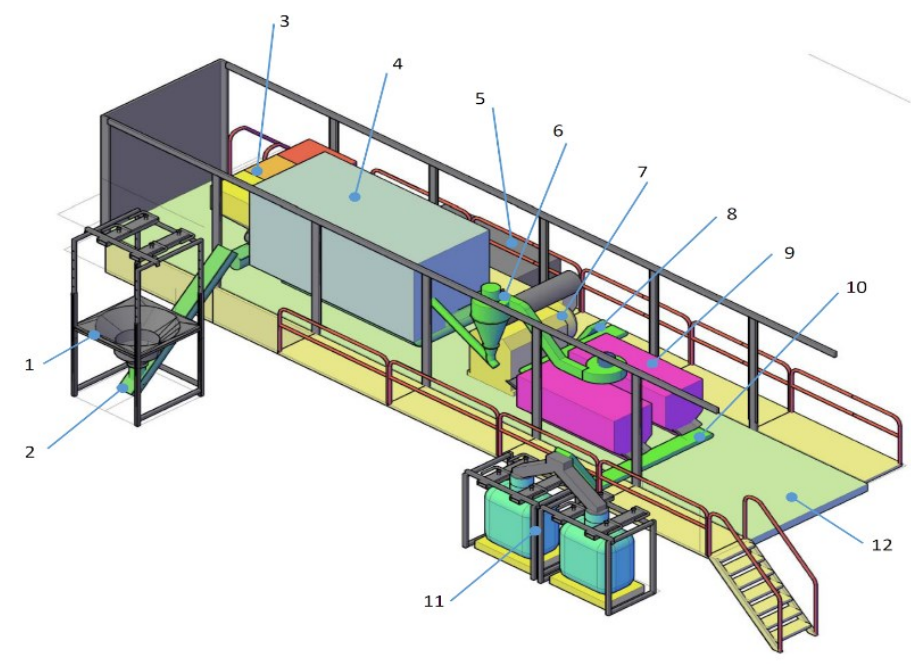

Fig. 2. 3D visualization of the designed line - view from the ash loading side.

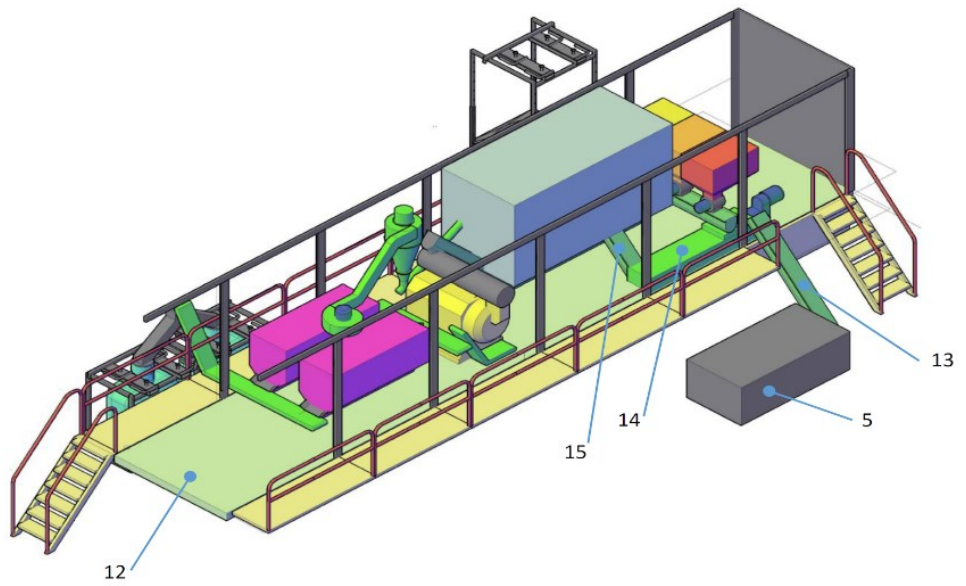

Fig. 3. 3D visualization of the designed line - view from the digestate loading side.

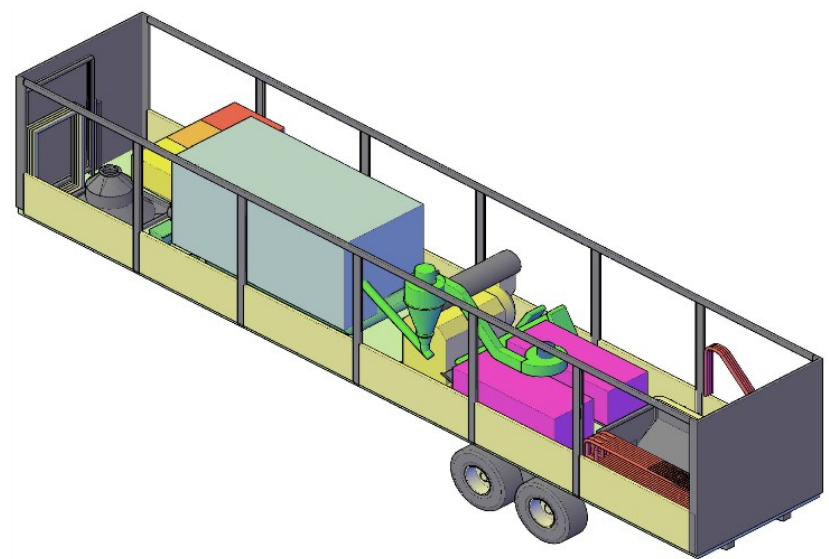

Fig. 4. 3D visualization of the designed line - view of transport position. 
Figure 4 presents the $3 \mathrm{D}$ visualization of the line in the transport position with all line elements arranged on the transport trailer.

\section{Summary}

The presented concept of a mobile technological line for the production of granulated fertilizer from mixtures of ash, digestete and valorising components in form of pellets takes into account all assumptions and in complex way allows for processing of raw materials with different and variable input parameters (different morphology and granulometric composition, moisture). Proposed mixtures stabilizing step allows to equalize the moisture content of mixtures components, what improves the quality of the obtained granules. The air dedusting system allows to clean the air before leaving the line and extracted dust returns to the granulation, this solution doesn't generate production waste during the process. The main innovation of the line is its mobility that allows the digestate to be processed at the place of its generation.

Research was funded by the National Centre for Research and Development and the National Fund for Environment Protection as a part of GEKON program - project no. GEKON1/05/214543/38/2015 "Proecology production of organic and mineral fertilizers based on waste: by-porducts of combusiton and biogasification of biomass".

\section{References}

1. M. Bavutti, L. Guidetti, G. Allesina, A. Libbra, A. Muscio, S. Pedrazzi, Energy Procedia 45, pp. 1344-1353 (2014) Doi:10.1016/j.egypro.2014.01.141.

2. G. Grinzi, L. Guidetti, G. Allesina, A. Libbra, P. Martini, A. Muscio, 20th European Biomass Conference and Exhibition (2012)

3. J. A. Alburquerque, C. Fuente, A. Ferrer-Costa, L. Carrasco, J. Cegarra, M. Abdad, M. P. Bernal, Biomass Bioenergy 40, pp. 181-189 (2012)

4. H. Döhler, P. Schliebner, Verfahren und Wirtschaftlichkeit der Gärrestaufbereitung. Darmstadt: KTBL (2006)

5. X. J. Huang, N. He, M. D. Liu, D. Yang, Y. J. Wang, Applied Mechanics and Materials 535, pp. 523-527 (2014)

6. L. C. Ram, R. E. Masto, Earth Sci. Rev. 128, pp. 52-74 (2014)

7. T. Kumar, K. Tedia, D. Devdas, Journal of Progressive Agriculture 6(1), pp. 78-82 (2015)

8. K. Mudryk, M. Wróbel, M. In The acquisition and processing of biomass of Virginia mallow for energy purposes. (ed. W. Piekarski). Wydawnictwo „Wieś jutra”, Warszawa, ISBN 978-83-62815-10-4 (2011)

9. M. Wróbel, J. Frączek, S. Francik, Z. Ślipek, K. Mudryk, Engineering for Rural Development Jelgava, Available at: http://tf.1lu.1v/conference/proceedings2013/Papers/121_Wrobel_M.pdf (2013) 